\title{
As representações sociais do trabalho do tutor presencial: limites e possibilidades
}

\section{The social representations of face-to-face tutoring: limits and possibilities}

\author{
Maria Luisa Furlan Costa ${ }^{1}$ \\ Maria Aparecida Crissi Knuppel ${ }^{2}$
}

\begin{abstract}
RESUMO
Neste artigo apresentamos uma discussão conceitual sobre o modelo de tutoria adotado pelas Instituições Públicas de Ensino Superior que integram o programa Universidade Aberta do Brasil (UAB). Toma-se como ponto de partida as pesquisas e as ações desenvolvidas pelas autoras nos últimos dez anos, que estão diretamente relacionadas com a educação a distância no Brasil. O foco central são os tutores presenciais que se responsabilizam pelo atendimento aos alunos no polo de apoio presencial e que são selecionados por meio de editais publicados nas páginas virtuais das instituições que ofertam cursos superiores em uma modalidade distinta do ensino presencial. A análise dos editais foi realizada com o intuito de verificar a relação entre as questões teóricas que vêm sendo trabalhadas pelos especialistas no Brasil e os requisitos exigidos para o exercício da tutoria. Acredita-se que a tutoria presencial é essencial para a promoção de ações educativas que contribuam para potencializar o aprendizado dos alunos.
\end{abstract}

Palavras-chave: educação; educação a distância; Brasil; tutor presencial.

\begin{abstract}
In this paper we discuss the tutoring model adopted by the Public Institutions of Higher Education that integrate the Open University of Brazil (Universidade Aberta do Brasil - UAB) program. The starting point is the research
\end{abstract}

DOI: $10.1590 / 0104-4060.38660$

1 Universidade Estadual de Maringá, Departamento de Fundamentos da Educação, Programa de Pós-Graduação em Educação (UEM/DFE/PPE). Maringá, Paraná, Brasil. Rua Osvaldo Cruz, 691. CEP: 87020-200.

2 Universidade Estadual do Centro-Oeste (Unicentro), Departamento de Letras. Guarapuava, Paraná, Brasil. Rua Padre Salvador, 875. CEP: 85015-430. 
and the actions developed by the authors in the past decade that are directly related to distance education in Brazil. The focus is on the classroom tutors who are responsible for assisting students in the presential center where they have support and who are selected through published notes in the virtual notice board of the institutions that offer higher education courses in a distinct mode of classroom teaching. The publication analysis was performed in a way to verify the relationship between the theoretical issues that have been studied by specialists in Brazil and the requirements for the exercise of tutoring. It is believed that face-to-face tutoring is essential for the promotion of educational activities that contribute to improve student progress and learning.

Keywords: education; distance education; Brazil; face-to-face tutoring.

\section{Introdução}

A Educação a Distância (EaD), de acordo com Belloni (2002), surgiu para atender às pessoas que não tinham condições de frequentar e acompanhar o ensino presencial. Em sua origem, foi vista como uma alternativa de educação possível para uma necessidade específica e intensificou-se como portadora de uma dimensão social relevante. Nesse sentido, observa-se que o processo de democratização do ensino sempre foi constante nos desafios da EaD, a educação como um direito efetivo dos cidadãos esteve presente desde as primeiras ações voltadas a essa modalidade.

Ao mencionar as características atuais da EaD, Belloni (2002) a conceitua como uma modalidade que traz em seu cerne as tecnologias de informação e comunicação (TIC) não dissociadas das práticas pedagógicas. A EaD é definida “[...] como parte de um processo de inovação educacional mais amplo, que é a integração das novas tecnologias de informação e comunicação nos processos educacionais" (BELLONI, 2002, p. 123).

As ações de EaD, no Brasil, se desenvolveram desde as primeiras décadas do século XX; entretanto, é por meio da Lei de Diretrizes e Bases da Educação (Lei $\mathrm{n}^{\circ}$ 9.394/96), em seu Artigo 80, que essa modalidade foi assumida em termos de legislação:

Art. 80. O Poder Público incentivará o desenvolvimento e a veiculação de programas de ensino a distância, em todos os níveis e modalidades de ensino, e de educação continuada. 
$\S 1^{\circ}$ A educação a distância, organizada com abertura e regime especiais, será oferecida por instituições especificamente credenciadas pela União. $\S 2^{\circ}$ A União regulamentará os requisitos para a realização de exames e registro de diploma relativos a cursos de educação a distância.

$\S 3^{\circ}$ As normas para produção, controle e avaliação de programas de educação a distância e a autorização para sua implementação, caberão aos respectivos sistemas de ensino, podendo haver cooperação e integração entre os diferentes sistemas.

$\S 4^{\circ}$ A educação a distância gozará de tratamento diferenciado. (BRASIL, 1996).

Pelo excerto do documento, verificam-se os preceitos legais de credenciamento institucional para a oferta de cursos na modalidade $\mathrm{EaD}$, os quais devem passar por processo de autorização que respeite as características e especificidades da modalidade.

A partir dessa Lei, a Portaria ${ }^{\circ} 4.361 / 2004$ regulamentou a forma de credenciamento das instituições de ensino e normatizou a autorização dos cursos superiores, os quais devem ter um projeto específico que apresente o papel social das Instituições de Ensino Superior (IES), as ações afirmativas para democratizar a educação superior, assim como as definições de tecnologias para a modalidade em estreita relação com a proposta pedagógica do curso.

De modo análogo, essa Portaria trouxe outros profissionais para as IES que atuam em $\mathrm{EaD}$ : professores pesquisadores, técnicos que auxiliam na produção e formatação do material, revisores de texto, especialistas em informática, equipe de coordenação, designers gráficos, tutores, entre outros. Tais profissionais encontram na modalidade outra forma de ressignificar o seu trabalho, no qual a cooperação, o conhecimento compartilhado e a conectividade são elementos essenciais e ao mesmo tempo desafiadores.

Em 2005, o Decreto $n^{\circ} 5.622$ regulamentou os Artigos 80 e 81 da LDBEN $\mathrm{n}^{\circ}$ 9.394/96 para as questões de credenciamento e de funcionamento dos cursos de educação a distância e definiu de forma conceitual a EaD:

[...] modalidade educacional na qual a mediação didático-pedagógica nos processos de ensino e aprendizagem ocorre com a utilização de meios e tecnologias de informação e comunicação, com estudantes e professores desenvolvendo atividades educativas em lugares ou tempos diversos (BRASIL, 2005). 
Tal documento, ao expor o termo "lugares ou tempos diversos" abre a perspectiva do trabalho nos polos, complementado com o Artigo 12, inciso VII: "[...] garantia de corpo técnico e administrativo qualificado" (BRASIL, 2005).

Esse Decreto orienta que o pedido de credenciamento para a EaD deve conter documentos que comprovem a existência de estrutura física e tecnológica e de recursos humanos necessários para a oferta da $\mathrm{EaD}$ e ainda valoriza o processo de formação continuada dos tutores, assumindo esse novo profissional no âmbito das ações da modalidade.

O Decreto ${ }^{\circ}{ }^{5} 5.800$, de 8 de junho de 2006, em seu Artigo $1^{\circ}$, institui o Sistema Universidade Aberta do Brasil (UAB), levando em consideração os resultados apresentados nos Programas Pró-Licenciatura Fases I e II, a operacionalização do Projeto Piloto em Administração Pública, bem como a parceria com a Associação Nacional de Dirigentes das Instituições Federais de Ensino Superior (ANDIFES) e empresas estatais:

Art.1ํ Fica instituído o Sistema Universidade Aberta do Brasil-UAB, voltado para o desenvolvimento da modalidade de educação a distância, com a finalidade de expandir e interiorizar a oferta de cursos e programas de educação superior no País.

Parágrafo único. São objetivos do Sistema UAB:

I - oferecer, prioritariamente, cursos de licenciatura e de formação inicial e continuada de professores da educação básica;

II - oferecer cursos superiores para capacitação de dirigentes, gestores e trabalhadores em educação básica dos Estados, do Distrito Federal e dos Municípios;

III - oferecer cursos superiores nas diferentes áreas do conhecimento;

IV - ampliar o acesso à educação superior pública;

$\mathrm{V}$ - reduzir as desigualdades de oferta de ensino superior entre as diferentes regiões do País;

VI - estabelecer amplo sistema nacional de educação superior a distância; e VII - fomentar o desenvolvimento institucional para a modalidade de educação a distância, bem como a pesquisa em metodologias inovadoras de ensino superior apoiadas em tecnologias de informação e comunicação (BRASIL, 2006).

Esse artigo e seus incisos são essenciais para se entender a inserção dos tutores nos Polos de Apoio Presencial, pois houve e há necessidade de expandir e interiorizar a oferta de cursos superiores públicos para as diferentes regiões do país, atendendo demandas específicas de formação de professores, de ges- 
tores e trabalhadores da educação básica, bem como de cursos estratégicos, de acordo com as demandas regionais. Na prática, isso somente seria possível se houvesse uma organização presencial mínima para receber os alunos, já que as universidades públicas não possuem uma rede tão delineada de campus ou extensões universitárias. Nesse cenário, se reveste a figura do tutor presencial como representativo de uma ação didático-administrativa e de apoio aos professores e discentes.

Os Referenciais de Qualidade para Educação Superior a Distância (BRASIL, 2007), documento norteador para a elaboração de propostas para cursos e sistemas de educação a distância, traz as seguintes premissas para o tutor presencial e a distância:

Em qualquer situação, ressalta-se que o domínio do conteúdo é imprescindível, tanto para o tutor presencial quanto para o tutor a distância e permanece como condição essencial para o exercício das funções. Esta condição fundamental deve estar aliada à necessidade de dinamismo, visão crítica e global, capacidade para estimular a busca de conhecimento e habilidade com as novas tecnologias de comunicação e informação (BRASIL, 2007, p. 22).

Para a formação dessa nova categoria, que ainda não se enquadra como profissional em termos legais, mas é de fato, os Referenciais apontam a necessidade de que as instituições desenvolvam planos de capacitação e formação de seu corpo de tutores prevendo três dimensões: capacitação no domínio específico do conteúdo; capacitação em mídias de comunicação; capacitação em fundamentos da $\mathrm{EaD}$ e no modelo de tutoria. Destacam ainda que o quadro de tutores para a execução de atividades pedagógicas e tecnológicas deve respeitar a relação numérica estudantes/tutor capaz de permitir interação no processo de aprendizagem.

A partir dos pressupostos elencados, entende-se que a educação a distância precisa, para além do aparato tecnológico e da estrutura física, do reconhecimento da estrutura de pessoal. Nesse sentido, considera-se relevante compreender esse cenário a partir da inserção de figuras representativas da modalidade e que se tornam marcos de identidade da $\mathrm{EaD}$ : os tutores presenciais ou tutores do polo, que se caracterizam como " [...] professores que dominem a metodologia e os conteúdos para que estabeleçam uma mediação competente junto aos alunos" (ENANFOPE, 2002, p. 29). 
Desta forma, neste artigo optou-se por buscar entender o papel desse profissional considerando três preocupações que suscitaram essa temática de pesquisa: 1) a pouca produção na literatura especializada sobre a função e o perfil do tutor presencial, pois há um destaque para pesquisas que investigam a atuação do tutor a distância ou on-line; 2) os discursos apresentados em encontros e seminários ${ }^{3}$ que evidenciam a necessidade do Polo de Apoio Presencial e de uma nova dimensão para atuação do tutor; 3) o que preceituam os Referenciais de Qualidade para a Educação Superior a Distância, que descortinam que as funções de tutoria (presencial e a distância) devem ser intercambiáveis para garantir o fortalecimento da modalidade.

Entende-se ainda que o papel que o tutor desempenha nas atividades de um curso, delineado nos projetos político-pedagógicos, deve ter uma relação direta com a concepção pedagógica, demonstrando claramente quais princípios do processo ensino-aprendizagem estão presentes nessa concepção.

A partir das premissas destacadas, se evidencia a problemática de pesquisa: qual a representação social do tutor presencial no desenvolvimento das atividades pedagógicas dos cursos, presente em editais de seleção desse profissional?

Essa temática se insere em uma pesquisa qualitativa que busca contribuir no desenvolvimento de trabalhos científicos na área de $\mathrm{EaD}$ e que tem como objetivo principal entender o papel do tutor presencial nas ações da modalidade, ciente que o termo tutor, carregado de toda a semântica de sua nomenclatura, aliado à representação de sua atividade profissional no âmbito das ações da $\mathrm{EaD}$, é ainda muito recente. Contudo, as funções e características da formação, perfil, atuação dos tutores tanto presenciais como a distância são objetos de estudos de pesquisadores como Gonzales, que afirma:

\begin{abstract}
No cenário da educação a distância, o papel do tutor extrapola os limites conceituais, imposto na sua nomenclatura, já que ele, em sua missão precípua, é educador como os demais envolvidos no processo de gestão, acompanhamento e avaliação dos programas. É o tutor o tênue fio de ligação entre os extremos do sistema instituição-aluno. O contato a distância impõe um aprimoramento e fortalecimento permanente desse elo, sem o que perde-se o foco (GONZALES, 2004, p. 1).
\end{abstract}

3 Os encontros referenciados são os Encontros Regionais de Polo e Mantenedores realizados em 2013 em seis cidades brasileiras (João Pessoa, Goiânia, Vitória, Florianópolis, Manaus e Montes Claros) e o Encontro Nacional de Coordenadores de Polo e mantenedores, realizado em fevereiro de 2014, em Brasília. 
Para muitos teóricos, o tutor é um dos principais pilares para o desenvolvimento das ações da $\mathrm{EaD}$, por ser um profissional que apoia o educando em sua trajetória, quer em termos de desenvolvimento específico da área do curso, quer em termos técnicos e tecnológicos.

Para delinear a abordagem deste artigo, algumas questões emergiram: 1) Quais as contribuições da tutoria presencial para o desenvolvimento dos cursos? 2) Qual o papel do tutor presencial na representatividade do Polo de Apoio Presencial?

Para entender de forma mais aprofundada a relação entre concepções pedagógicas, o perfil do tutor e as suas atribuições no processo ensino-aprendizagem, faz-se uma análise a partir de seis editais de seleção de tutores, do ano de 2013, publicados em portais de Instituições Públicas de Ensino Superior (IES) que integram o programa Universidade Aberta do Brasil (UAB), com o intuito de verificar a relação entre as questões teóricas apontadas pela literatura em $\mathrm{EaD}$ e as exigências contidas nos editais de seleção.

A linha de interpretação para este estudo centra-se na categoria de representação sustentada nos postulados defendidos por Chartier (1992, p. 10), pois esta permite entender "[...] a descrição das percepções, das representações e das racionalidades dos atores", ou seja, esquemas que dão sentido a uma realidade. Tal categoria auxilia a compreender qual a descrição do tutor presente nos editais que permite representá-lo como um profissional docente e qual o perfil exigido desses profissionais que lhe permite construir configurações múltiplas de uma realidade, não esquecendo que "cualquiera que sean las representaciones no mantienem nunca uma relación de inmediatez y de transparencia com las prácticas sociales que dan a leer e a ver" (CHARTIER, 1992, viii), mas são um modo de olhar, de significar e demarcar as representações que se tem desses atores no processo de educação a distância no âmbito do Sistema Universidade Aberta do Brasil.

Para auxiliar na análise do conceito de representação utiliza-se ainda a contribuição de Jodelet (2001), que sublinha:

[...] a representação social é sempre representação de alguma coisa e de alguém na qual as características do sujeito e do objeto se manifestam. A representação social simboliza e interpreta o objeto, substituindo-o e atribuindo-lhe sentido. A representação é construção e expressão do sujeito que se dá por meio de processos cognitivos e psíquicos, com a particularidade de incorporar, na análise dos processos, a pertença e a participação social e cultural do sujeito (JODELET, 2001, p. 11). 


\section{A arquitetura pedagógica dos cursos e a atuação do tutor presencial}

Para alguns teóricos da atualidade, vive-se, no momento presente, sob a égide da geração de ensino pela Internet ou aulas virtuais, baseada no desenvolvimento, sobretudo da Web 2.0, dos Repositórios de Recursos Educacionais Abertos (REAs) e no desenvolvimento das ferramentas de compartilhamento de conteúdos e materiais. No entanto, apontam para outra representação, por meio dos avanços da realidade aumentada e dos dispositivos móveis.

Contudo, para se evitar reducionismos que evidenciem uma concepção puramente técnica e tecnicista da educação a distância, há que se salientar que essa modalidade não é somente tecnologias e precisa ser compreendida:

[...] como uma prática educativa situada e mediatizada, uma modalidade de fazer educação, de democratizar o conhecimento. É, portanto uma alternativa pedagógica que se coloca ao educador com uma prática fundamentada numa racionalidade ética, solidária e compromissada com as mudanças sociais (PRETTI, 1996, p. 27).

Esse alerta é importante para que não se tenha uma interpretação equivocada da modalidade e, consequentemente, práticas pedagógicas neotecnicistas, sustentadas nas tecnologias de informação e comunicação.

Essa prática educativa envolve, como sugere Pretti (1996), uma estrutura organizacional que atenda a todos os componentes da modalidade: o aluno, os docentes, os tutores, o material didático, as concepções pedagógicas, o processo de avaliação, os mecanismos de controle da evasão e da reprovação, a estrutura de educação a distância nas instituições, a estrutura dos polos de apoio presencial e o ambiente virtual de aprendizagem. As características da EaD como democratização, autonomia, dialogicidade, individualização, socialização, abertura, educação permanente, flexibilidade e construcionismo contextualizado ganham destaque pelo uso das TIC ao evidenciar a EaD como um processo de ensino-aprendizagem mediado por tecnologias, em que professores, tutores e alunos estão separados espacial e/ou temporalmente, mas estão conectados, interligados por tecnologias (MORAN, 2012).

Com um maior número de pessoas acessando a Internet, surgiram novas possibilidades para os profissionais que atuam na modalidade a distância, os quais buscam alternativas que se coadunem com os estilos de aprendizagem 
dos educandos para construírem os princípios da arquitetura pedagógica de um curso que:

[...] é constituída por um conjunto de elementos (organizacionais, instrucionais, metodológicos e tecnológicos), os quais mantêm uma inter-relação [...]. Entre os elementos organizacionais da arquitetura pedagógica (AP), estão aqueles envolvidos na elaboração da proposta pedagógica e sua culminância: objetivos e finalidades da EAD, compreensão do tempo e do espaço [...], perfis dos sujeitos envolvidos no processo - o aluno, tutor e professor, bem como a definição das suas competências (BEHAR et al., 2009, p. 184).

Segundo a proposta de arquitetura pedagógica de Behar et al. (2009), o que constitui o projeto pedagógico de um curso é o constante processo de planejamento que considere a concepção pedagógica, o currículo, os planos de ensino, a formação continuada de docentes e tutores, o suporte da equipe multidisciplinar, os serviços oferecidos aos estudantes, o perfil e a atuação dos sujeitos envolvidos com a proposta: aluno, tutor e professor.

Tais pontos são a ancoragem para um processo de ensino e aprendizagem dinâmico, que auxilie na operacionalização dos aspectos pedagógicos, tecnológicos e organizacionais dos diferentes cursos, e novamente se destaca o papel do tutor.

No Sistema UAB, esse profissional é selecionado em edital público, pelas Instituições de Ensino Superior, para o exercício de uma atividade que previamente é descrita em edital, mas que pode ser ampliada de acordo com os princípios contidos no projeto pedagógico do curso, bem como de outras necessidades sociais e educacionais.

Mill et al. (2008) assinala duas categorias de tutores no sistema UAB: o tutor presencial e o tutor a distância.

Esses tutores podem, entretanto, ser divididos em duas categorias: uma pode ser denominada tutoria presencial e é composta pelo grupo de educadores que acompanha os alunos presencialmente, com encontros frequentes ou esporádicos; a outra categoria, denominada de tutoria virtual ou tutoria a distância, dedicada ao acompanhamento dos educandos virtualmente (a distância), por meio de tecnologias de informação e comunicação (MILL et al., 2008, p. 114). 
Por conseguinte, o tutor presencial atua no Polo e tem como finalidade fazer a orientação síncrona (ao mesmo tempo) para os alunos que estudam na modalidade de EaD, enfatizando a necessidade de se adquirir autonomia de aprendizagem.

A função precípua do tutor é a de contribuir para o sucesso de um curso por meio da criação de ações articuladas que envolvam aluno-professor-tutor em um sistema de orientação e de trocas em prol de um trabalho que se constrói e reconstrói mediante esquemas didáticos, oportunizando a construção de um caráter multidimensional.

Portanto, os tutores ao compreenderem sua função na modalidade, precisam construir campos de prática, conceito trabalhado por Barab e Duffy (2000). A defesa desses autores para esse conceito é a de que são " [...] entendidos como tarefas em que cada esforço é feito para tornar a atividade de aprendizagem autêntica em relação ao contexto social no qual as habilidades e os conhecimentos estão normalmente inseridos." (FILATRO, 2009, p. 98). Outro dispositivo que completa essa perspectiva é de que o relacionamento do indivíduo é potencializado na coletividade, não anulando a necessidade de uma ação individual.

O tutor pode possibilitar, tanto para o aluno quanto para o professor da disciplina, a cooperação e o apoio nas ações pedagógicas do curso. Essas relações entre professor-tutor e tutor-aluno se configuram com a mediação dos materiais didáticos, dos meios tecnológicos e pela ação coletiva de alunos, professores e tutores.

A nova configuração dada à EaD pelo avanço da tecnologia, pela inserção de Polos de Apoio Presencial, pelos princípios de democratização da educação devem, necessariamente, levar a um ensino de qualidade, em que a reflexão seja a tônica, pois sem ela não há a educação e, nesse espaço, o tutor que existe para a $\mathrm{EaD}$ e não para o ensino presencial faz a diferença na compreensão dos fundamentos da modalidade.

\section{A representação do tutor presencial e a representatividade do Polo}

No âmbito das pesquisas desenvolvidas sobre a EaD e nos cursos ofertados nessa modalidade existe uma representação positiva do Sistema de Tutoria, e na maioria das vezes a ênfase recai no papel do tutor on-line ou tutor a distância, que atua no Ambiente de Aprendizagem (AVA) de forma rotineira e cotidiana, e por mais que esteja distante fisicamente do aluno, acaba por estabelecer com este laços de companheirismo e auxílio na compreensão dos conteúdos. Por 
conseguinte, e conforme o modelo pedagógico de determinados cursos, a tutoria presencial é colocada em termos de uma atuação mais técnica do que pedagógica e, ainda, mais operacional do que didática.

Não se pode esquecer, contudo, que o Sistema UAB se materializa em uma tríade: o governo federal, as instituições públicas de ensino e os polos nos municípios onde os cursos são efetivamente ofertados e, nesse espaço, a atuação do tutor presencial precisa ser analisada e redimensionada, objeto maior deste artigo.

Ao analisar os editais para seleção de tutores no âmbito do Sistema UAB, observa-se que são organizados de maneira muito semelhante e atendem aos dispositivos de legislação no que se refere aos requisitos para ser um bolsista do Sistema UAB, critérios de seleção, contratação e remuneração dos tutores (BRASIL, 2007). Destarte, a Resolução CD/FNDE n 44, de 29 de dezembro de 2006, descreve as atividades dos tutores presenciais da seguinte forma:

Tutor Presencial - professor da rede pública estadual ou municipal, da cidade sede do polo, selecionado pelas Instituições de Ensino Superior vinculadas ao Sistema UAB, com formação de nível superior - licenciatura - e experiência comprovada de no mínimo um ano no magistério na educação básica [...] (BRASIL, 2007).

Em 2009, o Sistema Universidade Aberta do Brasil, por meio da Portaria n o 318, de 2 de abril de 2009, passa a ser incorporado pela Coordenação de Aperfeiçoamento de Pessoal de Nível Superior (Capes), cabendo a responsabilidade de avaliação e regulação à Secretaria de Educação a Distância. Tal mudança se pautou na necessidade de "[...] articular a Política Nacional de Formação de Profissionais do Magistério da Educação Básica ao Sistema Universidade Aberta do Brasil - UAB, bem como de disciplinar a formação de professores para a educação básica conforme parâmetros nacionais" (BRASIL, 2009).

A transferência desse sistema para a Capes traz outra dimensão política, pois a UAB passa a integrar um órgão institucionalizado e reconhecido no país em termos de fomento à pesquisa, articulador dos cursos de pós-graduação stricto sensu, responsável por cooperações nacionais e internacionais de inovação e pesquisa. Além disso, aponta o reconhecimento da Capes para com a modalidade a distância e o apoio à formação inicial e continuada de professores.

Essas mudanças delinearam um novo planejamento para as ações de $\mathrm{EaD}$ no Sistema Universidade Aberta do Brasil. Nesse sentido, houve uma adesão de mais IES públicas ao Sistema UAB, mudanças nas formas de organização 
da EaD nas Instituições Públicas de Ensino Superior, com um novo modelo de monitoramento e regularização dos polos e, assim, foi se configurando uma nova representatividade e identidade para os Polos UAB.

Nessa conjuntura, foi aprovada a Resolução $\mathrm{n}^{\circ} 26$ do CD/FNDE, de 5 de junho de 2009, a qual estabeleceu, entre outros princípios, a representação do tutor como profissional e, com isso, não há mais distinção entre tutor presencial e a distância. Foi, sem dúvida, um avanço, oriundo de muitas discussões junto à Diretoria de Educação a Distância (DED) da Capes, promovida por Coordenadores UAB e tutores que revindicavam, dentre outros pontos, a equiparação no valor das bolsas, tendo em vista que desde a primeira regulamentação até então em vigência cabia ao tutor presencial um valor de bolsa menor em relação ao tutor a distância.

Tal Resolução passou a exigir outros requisitos para a atuação de um tutor no Sistema UAB: formação em nível superior e experiência mínima de 1 (um) ano no magistério do ensino básico ou superior, ou formação pós-graduada, ou vínculo a programa de pós-graduação.

No anexo da referida Resolução estão descritas as atribuições do tutor, que indicam que não se espera um contato presencial efetivo desse profissional com os alunos, mas sim uma relação mediadora que se estabelece por meio do ambiente virtual de aprendizagem. Assim, o papel do tutor presencial de alguma forma se torna restrito, como se pode observar pelas descrições abaixo, nas quais se apresenta em um único item a ação desse profissional:

1. mediar a comunicação de conteúdos entre o professor e os cursistas;

2. acompanhar as atividades discentes, conforme o cronograma do curso;

3. apoiar o professor da disciplina no desenvolvimento das atividades docentes;

4. manter regularidade de acesso ao AVA e dar retorno às solicitações do cursista no prazo máximo de 24 horas;

5. estabelecer contato permanente com os alunos e mediar as atividades discentes;

6. colaborar com a coordenação do curso na avaliação dos estudantes;

7. participar das atividades de capacitação e atualização promovidas pela Instituição de Ensino;

8. elaborar relatórios mensais de acompanhamento dos alunos e encaminhar à coordenação de tutoria;

9. participar do processo de avaliação da disciplina sob orientação do professor responsável;

10. apoiar operacionalmente a coordenação do curso nas atividades presenciais nos polos, em especial na aplicação de avaliações (BRASIL, 2009). 
Diante dessa regulamentação, nos Polos do sistema UAB a figura do tutor presencial passa a ter uma nova dimensão - por exemplo, ela emerge para a categoria de Tutores de TCC e Tutores de Estágio, que passam a desempenhar papéis diferenciados nos Polos, no sentido de orientar os alunos em relação a normas técnicas e científicas de um trabalho de pesquisa, bem como de acompanhamento de alunos nas atividades de estágio, com o direcionamento do professor da disciplina.

Essa dimensão é importante, pois embora as atribuições constantes no documento legal não apontem distinções, na prática observa-se que outras funções, de acordo com os projetos pedagógicos dos cursos, estimulam a caracterização de novas atribuições para o tutor presencial, e os editais de seleção mostram claramente essa tendência, como, por exemplo, no excerto de um edital publicado por uma universidade estadual.

(1) Responsabilizar-se pelo registro de frequência dos alunos nos Polos;

(2) Participar de reuniões previamente agendadas, presenciais ou não, com professores, tutores (a distância), coordenação do curso, coordenação do Polo e coordenação do NEAD; (3) Ter disponibilidade de horários, dentro de sua carga horária, para atender os alunos no turno noturno e em finais de semana; (4) Desenvolver as atividades de acordo com o cronograma do curso, com o calendário e com a sua jornada de 20 horas semanais de trabalho; (5) Acompanhar os alunos nas atividades que serão realizadas presencialmente e no Ambiente Virtual de Aprendizagem Moodle; (6) Orientar os alunos na busca das informações necessárias para a organização dos estudos como aluno de educação a distância; (7) Trabalhar em equipe, colaborando nas atividades com os demais tutores, alunos e professores por meio do Ambiente Virtual de Aprendizagem Moodle do curso; (8) Enviar relatório sobre as atividades realizadas pelos alunos ao coordenador de tutoria do curso.

Essa diferenciação evidencia que na prática há distinções sobre o papel que cada um ocupa no desenvolvimento da modalidade. A análise do excerto permite visualizar que as atividades didáticas são executadas de forma diferenciada, fornece pistas para entender a proposta pedagógica do curso e aponta para a importância do Polo, ou seja, como um espaço que se configura como um campo de prática, na concepção de Barab e Duffy (2000), na medida em que se valorizam atividades didáticas como apoio acadêmico, orientação didática, entre outras, realizadas pelos estudantes com a orientação do tutor presencial. 
Exemplos como o exposto apontam um novo delineamento, ou seja, o de se evidenciar os espaços dos Polos com as marcas das ações do Sistema UAB. Essa visão traz uma nova forma de representatividade para o tutor presencial, que passa a ser entendido como um profissional ativo, o que se pode observar pelos editais analisados. Nos seis documentos utilizados como fontes para esta pesquisa verificam-se alguns pontos comuns na tutoria presencial:

a) conhecer o Projeto Político-Pedagógico do Curso ofertado pelo Polo;

b) atualizar os alunos quanto ao calendário acadêmico e demais atividades presenciais;

c) participar das reuniões de coordenação bem como interagir com os tutores a distância e professores das disciplinas, tanto de forma presencial, como virtual, via plataforma;

d) orientar os alunos quanto ao uso da plataforma Moodle, visando capacitá-lo para realização das atividades de ensino-aprendizagem do curso;

e) realizar atividades presenciais, incluindo avaliações, bem como auxiliar o tutor de apoio a distância em todos os momentos do encontro presencial;

f) participar dos fóruns de discussão incentivando o processo de interação;

g) propor grupos de estudos, encontros para discussão de temáticas dos módulos;

h) fornecer feedback ao professor da disciplina, ao coordenador do curso, de tutoria e tutores a distância sobre a qualidade do material didático e possíveis dificuldades de aprendizagem dos alunos.

Da análise das funções do tutor descritas acima, optou-se por enumerar 3 (três) pontos que se acredita serem fundamentais para entender a representação social desse profissional no âmbito da arquitetura pedagógica dos cursos e na representatividade do Polo de Apoio Presencial.

O primeiro ponto traz a representação acadêmica da instituição na qual atua. Tal representação encontra-se evidenciada nas alíneas a, b, c e h, ou seja, cabe ao tutor apoiar as atividades pedagógicas para que o aluno sinta-se parte de um ambiente acadêmico, por mais que esteja fisicamente longe de um campus universitário e sim em um Polo. Esse processo precisa ser dialógico, permeado por relações de confiança e de apoio ao desenvolvimento de conteúdos, metodologias, atividades, ao mesmo tempo em que por meio dessas interações o tutor possa entender o contexto de produção de conhecimento por parte dos acadêmicos.

A esse respeito, cita-se Gonzales, para quem: 
A relação pedagógica conclama a uma construção cotidiana. Sozinho, o aprendiz caminha vacilante, perdendo o rumo desejado. Nisso o tutor pode ampará-lo, conduzi-lo e encaminhá-lo. À medida que o processo de aprendizagem se efetiva, a relação do aluno com o tutor muda, se aprofunda, estreitando o laço afetivo, propiciando a permeabilidade educativa, uma vez que a educação deve ser vista sempre como uma prática social ligada à formação de valores e práticas do indivíduo para a vida social, com possibilidade de ir em direção a uma maior autonomia, liberdade e diferenciação [...] (GONZALES, 2004, p. 1).

Um segundo ponto evidencia a representação do tutor por parte dos professores e coordenadores do curso, pois esses consideram a atuação do tutor como um dos alicerces para o sucesso da EaD. No entanto, a maior ênfase recai no processo de interação entre professor-aluno-tutor virtual em contraposição ao tutor presencial, e sua tarefa, por vezes, fica negligenciada, ao incumbi-lo de questões mais administrativas e operacionais do Polo e no acompanhamento de encontros e avaliações presenciais, como se observa na alínea "c" da citação em análise.

Oliveira (2008) revela que o tutor é o elemento do sistema de EaD que personifica a modalidade e representa o lado humano das ações didáticas.

[...] esta figura quem lida diretamente com o estudante, seja para prestar esclarecimentos administrativos, seja no processo de ensino e aprendizagem, na avaliação do processo formativo do estudante ou, simplesmente, na monitoria das atividades dos estudantes. Por isso, é considerado o 'fator humanizador' do sistema de educação na modalidade a distância (OLIVEIRA, 2008, p. 30).

Um terceiro delineamento aponta para a função de acompanhamento da trajetória acadêmica dos alunos e, portanto, torna-se uma atividade que ganha similaridade com a atuação do professor, quer individual ou coletivamente. Entretanto, há que se ter clareza de que os conhecimentos para exercer a função de tutoria ao mesmo tempo em que envolvem elementos da docência se particularizam, pois esse profissional precisa compreender a forma escolar. Nesse contexto, Machado, L. e Machado, E. C. (2004) pontuam que os tutores precisam entender a estrutura do assunto que ensinam, os princípios da sua organização conceitual e os princípios das novas ideias produtoras de conhecimento na área. 
Para Mill et al. (2008, p. 115), há uma diferença entre o professor do ensino presencial e o tutor: embora o tutor seja um docente, "não pode ser chamado de professor pelo fato de não haver aula propriamente dita na educação a distância, mas o tutor é, legitimamente, um docente" que promove a realização de atividades didáticas, auxilia os educandos na compreensão dos conteúdos de uma forma aprofundada.

\section{Novas representações para o tutor presencial}

A tutoria no ambiente presencial, como especificado, possibilita diversos modos de se realizar o acompanhamento dos alunos, mas sua representação precisa ser ressignificada, pois uma identidade profissional é um assunto sério e remete a um espaço de construção de um determinado perfil.

Defende-se aqui que o tutor não é apenas quem acompanha os aspectos estruturais e de apoio ao estudante, e tampouco é somente o mediador do processo de aprendizagem, e nem ainda o docente responsável pelas disciplinas ou atividades de ensino. A atuação pedagógica do tutor aproxima-se do que foi abordado anteriormente e vai além; e essa nova representação já aparece, embora timidamente, em um dos editais analisados, como se visualiza no excerto abaixo:

a) interagir com os alunos nas diversas atividades em sala de aula no Polo de atuação;

b) viabilizar atividades culturais, interdisciplinares, videoconferências, grupos de discussões presenciais e avaliações previstas no calendário acadêmico;

c) articular ações entre os estudantes, Coordenador de Polo, de Curso e de Tutoria, visando à troca de experiências e/ou solução de demandas acadêmicas;

d) postar as atividades realizadas no Polo de atuação.

A tutoria presencial é essencial para a promoção de ações educativas que contribuam para potencializar o aprendizado dos alunos e como locus privilegiado de formação de conhecimentos que podem e devem ser disponibilizados para alunos do seu e de outros Polos, para a comunidade em geral, para os tutores, em um processo contínuo de troca de experiências.

Para tanto, alguns pontos são básicos e merecem ser elencados à guisa de considerações, para que o papel do tutor presencial possa ser redimensionado: 
1) Para que se obtenha os resultados esperados em uma atuação diferenciada, há a necessidade que o tutor presencial domine o conteúdo da(s) disciplina(s) em que atua, utilize estratégias pedagógicas que tornem o aprendizado significativo, seja um estudioso das novas tecnologias e de sua aplicabilidade, desempenhe um papel político de articulação com o conselho do polo e com a comunidade em geral;

2) Caberia ao tutor presencial, a partir das atividades do curso em que atua, a promoção de eventos, projetos e outras atividades que estabeleçam uma relação não só com os acadêmicos, mas também com a comunidade, para que esta se sinta partícipe do espaço educacional do Polo, e assim, este se torne representativo na sociedade em que está inserido;

3) Dada a especificidade de seu trabalho, a formação desse profissional deve corresponder às exigências dos projetos pedagógicos dos cursos, devendo ainda participar ativamente de projetos de formação continuada;

4) É função do tutor criar um ambiente acolhedor no Polo para receber os alunos e realizar nesse espaço práticas de acolhimento ou de recepção, que envolvam desde a formação para o uso das tecnologias e do ambiente virtual de aprendizagem, além de realizar uma avaliação diagnóstica dos alunos e, em planejamento conjunto com o coordenador de tutoria e com os professores dos cursos, organizar programas de adaptação curricular para acadêmicos, em forma de minicursos, grupos de estudos, seminários, entre outras práticas pedagógicas. Nessa proposição, o tutor presencial passaria a ter um papel de instigar a aprendizagem e auxiliar na permanência do aluno no curso, evitando a desistência; 5) Ser partícipe de uma rede que envolva colegas de outros Polos e tutores a distância para dialogar sobre estratégias de melhoria de ensino e de combate à evasão.

O que se vislumbra é um papel ativo para o tutor presencial que seja intercambiável com o papel do tutor a distância, mas que tenha suas singularidades e, ainda, que esse profissional tenha uma representação social construída pela própria condição concreta do seu trabalho.

\section{REFERÊNCIAS}

ANDRADE, E. M. de. As práticas pedagógicas do tutor na Educação a distância. In: Anais do IX Seminário Pedagogia em Debate e IV Colóquio Nacional de Formação de Professores. Curitiba: Universidade Tuiuti do Paraná, 2009. 
BARAB, S.; DUFFY, T. From practice fields to communities of practice. In: Theoretical foundation of learning environments. Mahwah: Erlbaum, 2000.

BEHAR, P. A. et al. Modelos pedagógicos para a Educação a distância. Porto Alegre: Artmed, 2009.

BRASIL. Ministério da Educação. Lei nº 9.394, de 20 de dezembro de 1996. Estabelece as diretrizes e bases da educação nacional. Diário Oficial da União, Brasília, DF, 23 dez. 1996. Disponível em: <http://portal.mec.gov.br/SEED/arquivos/pdf/tvescola/leis/ lein9394.pdf>. Acesso em: 28 mar. 2014.

BRASIL. Ministério da Educação. Portaria n ${ }^{\circ} 4.361$, de 29 de dezembro de 2004. Diário Oficial da União, Brasília, DF, 30 dez. 2004. Disponível em: <http://www2.mec.gov.br/ sapiens/portarias/port4361.pdf>. Acesso em: 27 mar. 2014.

BRASIL. Decreto $n^{\circ} 5.622$, de 19 de dezembro de 2005. Regulamenta o art. 80 da Lei no 9.394, de 20 de dezembro de 1996, que estabelece as diretrizes e bases da educação nacional. Diário Oficial da União, Brasília, DF, 20 dez. 2005. Disponível em: <http:// www.mec.gov.br>. Acesso em: 1 abr. 2014.

BRASIL. Decreto ${ }^{\circ} 5.800$, de 8 de junho de 2006. Dispõe sobre o Sistema Universidade Aberta do Brasil - UAB. Diário Oficial da União, Brasília, DF, 9 jun. 2006. Disponível em: <http://www.mec.gov.br>. Acesso em: 2 abr. 2014.

BRASIL. Fundo Nacional de Desenvolvimento da Educação. Resolução nº 44, de 29 de dezembro de 2006. Diário Oficial da União, Brasília, DF, 2 jan. 2007.

BRASIL. Resolução n ${ }^{\circ}$ 26, de 5 de junho de 2009. Diário Oficial da União, Brasília, DF, 8 jun. 2009.

BRASIL. Ministério da Educação. Portaria Ministerial no 318, de 2 de abril de 2009. Transfere à Coordenação de Aperfeiçoamento de Pessoal de Nível Superior - CAPES a operacionalização do Sistema Universidade Aberta do Brasil - UAB. Diário Oficial da União, no 64, Brasília, DF, 3 abr. 2009.

BRASIL. Ministério da Educação. Referenciais de Qualidade para a Educação Superior a Distância. Disponível em: <http://portal.mec.gov.br/seed/arquivos/pdf/legislacao/ refead1.pdf>. Acesso em: 20 abr. 2014.

BELLONI, M. L. Ensaio sobre a educação a distância no Brasil. Revista Educação \& Sociedade, Campinas, Unicamp, v. 23, n. 78, p. 117-142, abr. 2002.

CHARTIER, R. El mundo como representación: estudios sobre historia cultural. Barcelona: Gedisa, 1992.

ENCONTRO NACIONAL DA ASSOCIAÇÃO NACIONAL PELA FORMAÇÃO DOS PROFISSIONAIS DA EDUCAÇÃO - Enanfope, 11. 2002. Documento final XI. Florianópolis, Anfope, 2002. 
FILATRO, A. As teorias pedagógicas fundamentais em EAD. In: LITTO, F. M.; FORMIGA, M. (Orgs). Educação a distância: o estado da arte. São Paulo: Pearson Education do Brasil, 2009.

GONZALES, M. A arte da sedução pedagógica na tutoria em Educação a distância. Ministério da Educação e Cultura - SEED - Proinfo Abril, 2004.

JODELET, D. Representações Sociais: um domínio em expansão. In: JODELET, D. As representações sociais. Rio de Janeiro: Eduerj, 2001.

LITWIN, E. (Org.). Educação a distância: temas para debate de uma nova agenda educativa. Porto Alegre: Artmed, 2001.

MACHADO, L. de; MACHADO, E. de C. O papel da tutoria em ambientes de EAD. In: XI CONGRESSO INTERNACIONAL DA ABED, Salvador, 7-9 set. 2004. Disponível em: <http://www.abed.org.br/congresso2004/por/htm/022-tc-a2.htm>. Acesso em: 18 mar. 2014.

MILL, D. R. Reflexões sobre a Formação de Professores pela/para Educação a distância na contemporaneidade: convergências e tensões. In: DALBEN, A. I. L. de F. (Org.). Convergências e tensões no campo da formação e do trabalho docente. Belo Horizonte: Autêntica, 2010. p. 295-314. (Didática e Prática de Ensino).

MILL, D. R. et al. O desafio de uma interação de qualidade na educação a distância: o tutor e sua importância nesse processo. Cadernos da Pedagogia, São Carlos, ano 2, v. 2, n. 4, p. 112-127, ago./dez. 2008.

MORAN, J. M. O que é Educação a distância. 2002. Disponível em: <http://www.eca. usp.br/prof/moran>. Acesso em: 10 out. 2012.

OLIVEIRA, G. M. S. de. Concepções de orientadores acadêmicos e estudantes dos cursos de pedagogia a distância da Universidade Federal de Mato Grosso sobre ensino e aprendizagem. Tese (Doutorado em Educação) - Programa de Pós-Graduação, Universidade Federal de Santa Catarina, Florianópolis, 2008.

PRETTI, O. Educação a Distância: início e indícios de um percurso. In: Educação a distância: uma prática educativa mediadora e mediatizada. Cuiabá: NAED/IE - UFMT, 1996.

PRETTI, O. Uma prática educativa mediadora e mediatizada. Disponível em: $<$ http:// www.nead.ufmt.br/index.asp?pg=7>. Acesso em: 9 out. 2012.

Texto recebido em 22 de novembro de 2014. Texto aprovado em 10 de dezembro de 2014. 
